\title{
A glycolipid adjuvant, 7DW8-5, provides a protective effect against colonic inflammation in mice by the recruitment of CD1d-restricted natural killer T cells
}

\author{
Chansu Lee ${ }^{1}$, Sung Noh Hong ${ }^{2}$, Young-Ho Kim² \\ ${ }^{1}$ Samsung Biomedical Research Institute, Samsung Medical Center, Seoul; ${ }^{2}$ Department of Medicine, Samsung Medical Center, Sungkyunkwan \\ University School of Medicine, Seoul, Korea
}

Background/Aims: The modulation of CDld-restricted natural killer T (NKT) cells by glycolipids has been considered as a potential therapy against immunologic diseases, including inflammatory bowel disease. A recently identified a glycolipid ana$\log$, 7DW8-5, which is derived from $\alpha$-galactosylceramide ( $\alpha$-GalCer), is as much as 100 -fold more active at stimulating both human and mice NKT cells when compared to $\alpha$-GalCer. We explored the effects of 7DW8-5 in mouse models of acute and chronic colitis. Methods: We investigated the effects of 7DW8-5 on intestinal inflammation by assessing the effects of 7dW8-5 on a murine dextran sulfate sodium (DSS)-induced acute colitis model and a chronic colitis-associated tumor model. Results: The acute DSS-induced colitis model showed a dose-dependent response to 7DW8-5, as mice administered 7DW8-5 showed a significant improvement in DSS-induced colitis based on their disease activity index, histologic analysis, and serum C-reactive protein levels, when compared to mice administered vehicle alone. However, DSS-induced colitis in CD1d-KO mice showed no response to 7DW8-5. A fluorescence-activating cell sorting analysis revealed an increase in NKT cells in colonic tissues of 7DW8-5-treated mice. RNA-seq and real-time quantitative polymerase chain reaction showed a significant increase in the expression of interleukin (IL)-4, IL-13, and interferon-gamma in 7DW8-5-treated mice. In addition, 7DW8-5 treatment reduced colitis-associated tumor development in an azoxymethane/DSS mouse model. Conclusions: 7DW8-5 activates NKT cells through CDld and provides a protective effect against intestinal inflammation in mice. Therefore, 7DW8-5 may be a promising therapeutic agent for treatment of inflammatory bowel disease. (Intest Res 2020;18:402-411)

Key Words: 7DW8-5; Alpha-galactosylceramide; Natural killer T-cells; Dextran sulfate sodium; Inflammatory bowel disease

\section{INTRODUCTION}

Certain types of glycolipids have remarkable immunomodulatory properties that arise from their ability to activate specific T lymphocyte populations that have a wide range of im-

Received October 16, 2019. Revised January 5, 2020

Accepted January 8, 2020.

Correspondence to Sung Noh Hong, Department of Medicine, Samsung

Medical Center, Sungkyunkwan University School of Medicine, 81 Irwon-ro,

Gangnam-gu, Seoul 06351, Korea. Tel: +82-2-3410-1927, Fax: +82-2-3410-

6983,E-mail: gisnhong@gmail.com

Co-Correspondence to Young-Ho Kim, Department of Medicine, Samsung Medical Center, Sungkyunkwan University School of Medicine, 81 Irwon-ro, Gangnam-gu, Seoul 06351, Korea. Tel: +82-2-3410-3409, Fax: +82-2-34106983,E-mail: bowelkim@gmail.com mune effector properties. ${ }^{1}$ The most extensively studied glycolipid reactive $\mathrm{T}$ cells are the CD1d-restricted natural killer $\mathrm{T}$ (NKT) cells, which are characterized by the expression of semi-invariant T cell receptor (TCR) and surface antigens that are typically associated with NK cells (NK1.1). ${ }^{2,3}$ The TCR on NKT cells is unique in that it recognizes glycolipid antigens presented by the major histocompatibility complex I-like molecule, CD1d. ${ }^{4,5}$ Once activated, NKT cells can secrete a very diverse array of pro- and anti-inflammatory cytokines to modulate innate and adaptive immune responses. ${ }^{1}$ NKT cells account for only a small percentage of lymphocytes; however, they are extremely potent and play central roles in immunity to infection, in some cancers, and in autoimmunity. ${ }^{6-8}$ Thus, 


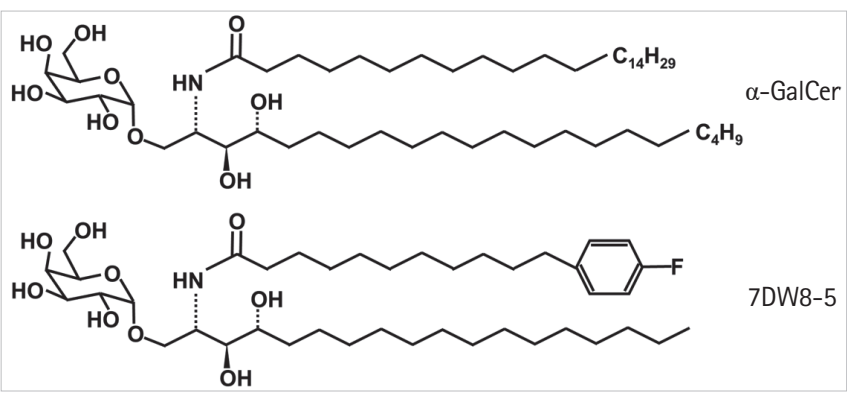

Fig. 1. Structure of $\alpha$-galactosylceramide ( $\alpha$-GalCer) and 7DW8-5.

glycolipid-mediated activation of NKT cells has been explored for immunotherapy in a variety of infectious disease and cancers. ${ }^{1}$

Alpha-galactosylceramide (KRN7000, $\alpha$-GalCer) was originally recognized for its antimetastatic properties in a marine sponge, and it became the first known CD1d-presented lipid antigen for NKT cells. ${ }^{9}$ The synthetic form of $\alpha$-GalCer is widely studied and is the best-known glycolipid antigen for activating NKT cells, both in vivo and in vitro. ${ }^{10-12}$ However, $\alpha$-GalCer displays only marginal biological activity. ${ }^{12}$ A novel analog of $\alpha$-GalCer (Fig. 1), 7DW8-5, has recently been identified. Stepwise screening assays confirm 7DW8-5 as a glycolipid that is as much as 100 -fold more active at stimulating both human and mouse NKT cells when compared to $\alpha$-GalCer. ${ }^{11}$ 7DW8-5 has shown superior effects to $\alpha$-GalCer as a malaria vaccine adjuvant in mouse models. ${ }^{12,13} 7 \mathrm{DW} 8-5$ is also viewed as a promising immunotherapeutic agent; however, its effects are not yet well defined with respect to autoimmunity and inflammation. One commonly used experimental inflammation model is the mouse dextran sulfate sodium (DSS)-induced colitis model of inflammatory bowel disease (IBD). This model affords a high degree of uniformity and reproducibility for most lesions in the colon. The DSS model has confirmed an involvement of CD1d-mediated activation of NKT cells in improvement of the colitis symptoms induced by DSS administration. ${ }^{14}$ In the present study, we used this model to investigate the effects of 7DW8-5 on colitis progression in DSS-induced mice and to define the changes in immune responses induced by activated NKT cells and mediated by 7DW8-5 treatment.

\section{METHODS}

\section{Design of the Animal Experiment}

C57BL/6 (wild type, WT) and C57BL/6-Cd1d1/J (CD1d knock- out, $\mathrm{CDld}^{-/}$) mice, 6 to 8 weeks old, were purchased from the Jackson laboratory (Sacramento, CA, USA). All mice were maintained in a temperature- and light-controlled facility and allowed ad libitum access to water and pellet chow. All animal experiments were approved by the Institutional Animal Care and Use Committee of the Samsung Medical Center (IACUC No. 20150105005).

\section{Acute Colitis Model}

Acute colitis in mice was induced in mice by supplying DSS (MP Biomedicals, Santa Ana, CA, USA) in the drinking water at a $4 \%$ concentration. 7DW8-5 was purchased from the Funakoshi Company (Tokyo, Japan) and dissolved in dimethyl sulfoxide following the manufacturer's recommendation. The optimal dosage of 7DW8-5 was determined by administering 10, 50,100 , and $200 \mu \mathrm{g}$ of 7DW8-5 per $1 \mathrm{~kg}$ of mouse body weight intraperitoneally to a minimum of 3 acute colitis model mice. The body weight change and colitis activity of the mice administered different dosages of 7DW8-5 were compared to those of 5 WT mice administered $\alpha$-GalCer.

The effects of 7DW8-5 in the acute colitis model were evaluated by administering 7DW8-5 (DSS/7DW8-5 group, $\mathrm{n}=10$ ) or vehicle (DSS/vehicle group, $\mathrm{n}=10$ ) intraperitoneally at day 0 and repeating this administration every 48 hours. Day 0 was determined as the day of first administration of DSS and 7DW8-5 or vehicle. All groups of mice were sacrificed on day 7. The $\mathrm{CDld}^{-/-}$mice were given a dose of only $100 \mu \mathrm{g} / \mathrm{kg}$ body weight of 7DW8-5 (CD1d $^{-/}$DSS/7DW8-5 group, $\mathrm{n}=6$ ) or vehicle (CD1d ${ }^{-/}$DSS/vehicle group, $\left.\mathrm{n}=6\right)$ intraperitoneally. In addition, $200 \mathrm{mg}$ of anti-NK1.1 was injected to WT mice intraperitoneally on day -1 to abolish NKT cell pharmacologically. Subsequently, DSS-induced colitis was induced with administration of 7DW8-5 (anti-NK1.1/DSS/7DW8-5 group, $\mathrm{n}=3$ ) or vehicle (anti-NK1.1/DSS/vehicle group, $\mathrm{n}=3$ ) intraperitoneally.

Colitis activity was monitored by scoring the disease activity index (DAI) on day 2, 4, and 6, as follows: ${ }^{14}$ Weight loss: 0 (no loss), 1 (1\%-5\%), 2 (5\%-10\%), 3 (10\%-20\%), and 4 (>20\%); Stool consistency: 0 (normal), 2 (loose stool), and 4 (diarrhea); Bleeding: 0 (no blood), 1 (hemoccult positive), 2 (hemoccult positive and visual pellet bleeding), and 4 (gross bleeding, blood around anus). A blood sample was obtained from each mouse at day 7. After sacrificing the mice, the colonic tissues were harvested and used for the measurement of colon length, RNA precipitation, single cell suspension for flow cytometry, and histologic analyses. 


\section{Chronic Colitis-Induced Tumor Model (AOM/DSS Model)}

The effects of 7DW8-5 on colitis-induced tumors were investigated by injecting mice intraperitoneally with azoxymethane (AOM; Sigma-Aldrich, St. Louis, MO, USA) at a dose of 7.4 $\mathrm{mg} / \mathrm{kg}$ body weight at day 0 . At the same time, $3 \%$ DSS was supplied in the drinking water and maintained until day 4 . The drinking water was then changed to regular water and maintained until day 14 . This induction cycle was repeated twice. 7DW8-5 or vehicle were then administered to the mice every 48 hours during the DSS supply period and every 72 hours in the water supply period. All mice in all groups were sacrificed at day 45. After sacrificing the mice, colon tissues were harvested and the numbers of tumor $\geq 1 \mathrm{~mm}$ in diameter were counted after $4 \%$ indigo carmine staining.

\section{Histological Analysis and Histological Scoring}

Formalin-fixed, paraffin-embedded tissue was sectioned and stained with H\&E via standard methods. Histologic scores were determined using a combined score of severity of inflammation, crypt damage, and ulceration. The histological scoring was defined as follows: ${ }^{15}$ Severity of inflammation: 0 , rare inflammatory cells in the lamina propria; 1 , increased numbers of granulocytes in the lamina propria; 2 , confluence of inflammatory cells extending into the submucosa; and 3 , transmural extension of the inflammatory infiltrate. Crypt damage: 0 , intact crypts; 1, loss of the basal one-third; 2, loss of the basal twothirds; 3 , entire crypt loss; 4 , change of epithelial surface with erosion; and 5, confluent erosion. Ulceration: 0, absence of ulcer; 1 , one or two foci of ulcerations; 2 , three or four foci of ulcerations; and 3, confluent or extensive ulceration.

\section{RNA Extraction and Real-Time Quantitative PCR}

Total RNA was extracted from appropriate cells using an RNeasy Mini Kit (QIAGEN, Hilden, Germany) and the concentration measured with an ND-1000 Spectrophotometer (NanoDrop Technologies, Wilmington, DE, USA). The realtime quantitative polymerase chain reaction (qPCR) assays were run using 1-5 $\mu$ g RNA per sample using a qScript ${ }^{\mathrm{TM}}$ One-STEP qRT-PCR Kit (Quanta Biosciences, Beverly, MA, USA). Relative mRNA expression levels were measured by quantitative PCR using a TaqMan probe (BD Bioscience, San Jose, CA, USA). The plate documentation/experimental parameters for qPCR followed the manufacturer's instructions and analysis was done using a 7300 real-time PCR detection system (BD Bioscience). Three independent qPCR reactions were performed and target mRNA levels were normalized relative to $\beta$-actin expression levels.

\section{Measurement of Serum CRP Level}

The serum level of C-reactive protein (CRP) was measured in mouse blood obtained at day 7 using a mouse CRP ELISA kit (R\&D Systems, Minneapolis, MN, USA). ELISA assays were performed in accordance with the manufacturer's instructions. The optical densities of the samples were determined using a microplate reader set at $450 \mathrm{~nm}$. The experiments were run in triplicate.

\section{Fluorescence-Activating Cell Sorting}

Single cell suspensions were prepared from the colon tissues and incubated in DMEM (Dulbecco's modified Eagle's medium) with collagenase 1 (Sigma-Aldrich) and dispase (Sigma-Aldrich) for 1 hour. After incubation, the cells were collected by filtering the cell solution through a $40 \mu \mathrm{m}$ strainer. The flow cytometry analysis was conducted on $5 \times 10^{4}$ cells to detect each marker. Cells were incubated for 20 minutes in the presence of an appropriate dose of antibodies in fluorescence-activating cell sorting (FACS) buffer. In this study, we used antimouse CD3e (BD bioscience), NK1.1 (BD bioscience), and Cdld tetramer (Proimmune Ltd., Oxford, UK) to measure the population of NKT cells. Colonic NKT cells were sorted by first enriching the stained cells for CD3+ leukocytes and the CD3enriched samples were then sorted with anti-NK1.1 and CD1d tetramer. Cell sorting was conducted using a FACS Aria 1 instrument (BD Bioscience). The percentages of cell populations were calculated by acquiring a total of 10,000 events.

\section{RNA Sequencing}

Total RNA was extracted from colonic tissues obtained from DSS/vehicle mice ( $\mathrm{n}=3)$, DSS/7DW8-5 mice $(\mathrm{n}=3)$, and DSS/ $\alpha$-GalCer mice $(n=2)$. An mRNA library was constructed and sequencing was carried out using the $100 \mathrm{bp}$ paired-end mode of the TruSeq Rapid PE Cluster kit and TruSeq Rapid SBS kit. The RNA sequencing data were subjected to quality control, and then the trimmed reads were mapped to a reference genome with the TopHat splice-aware aligner, and the transcript was assembled by Cufflinks with aligned reads that contained pairedend information. The fragments per kilobase of transcript per million mapped reads of assembled transcripts were calculated for each sample using Cufflinks. All RNA-seq experiments and analyses were performed by Macrogen (Seoul, Korea). 
A

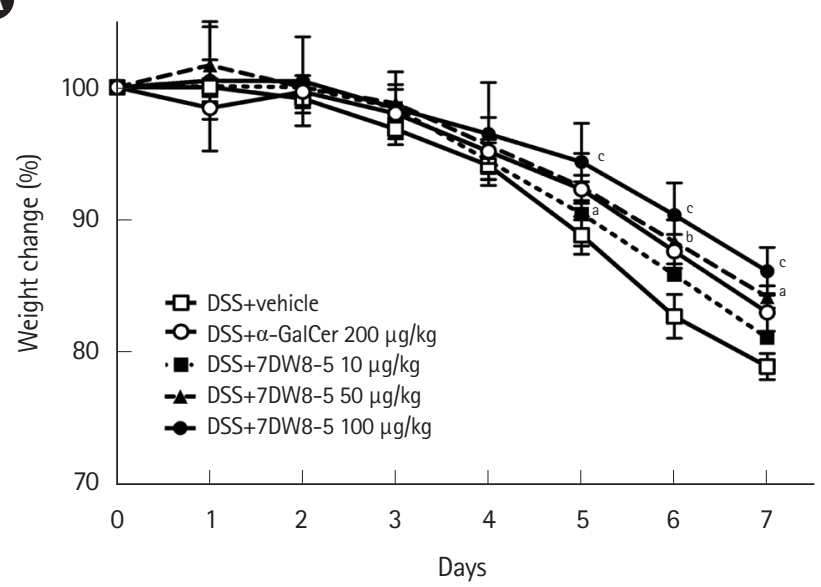

B

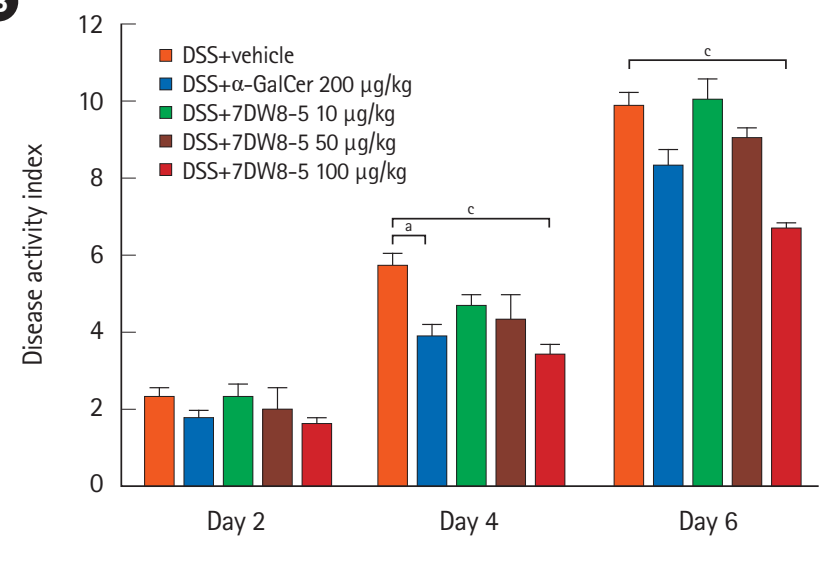

C

$4 \%$ DSS +
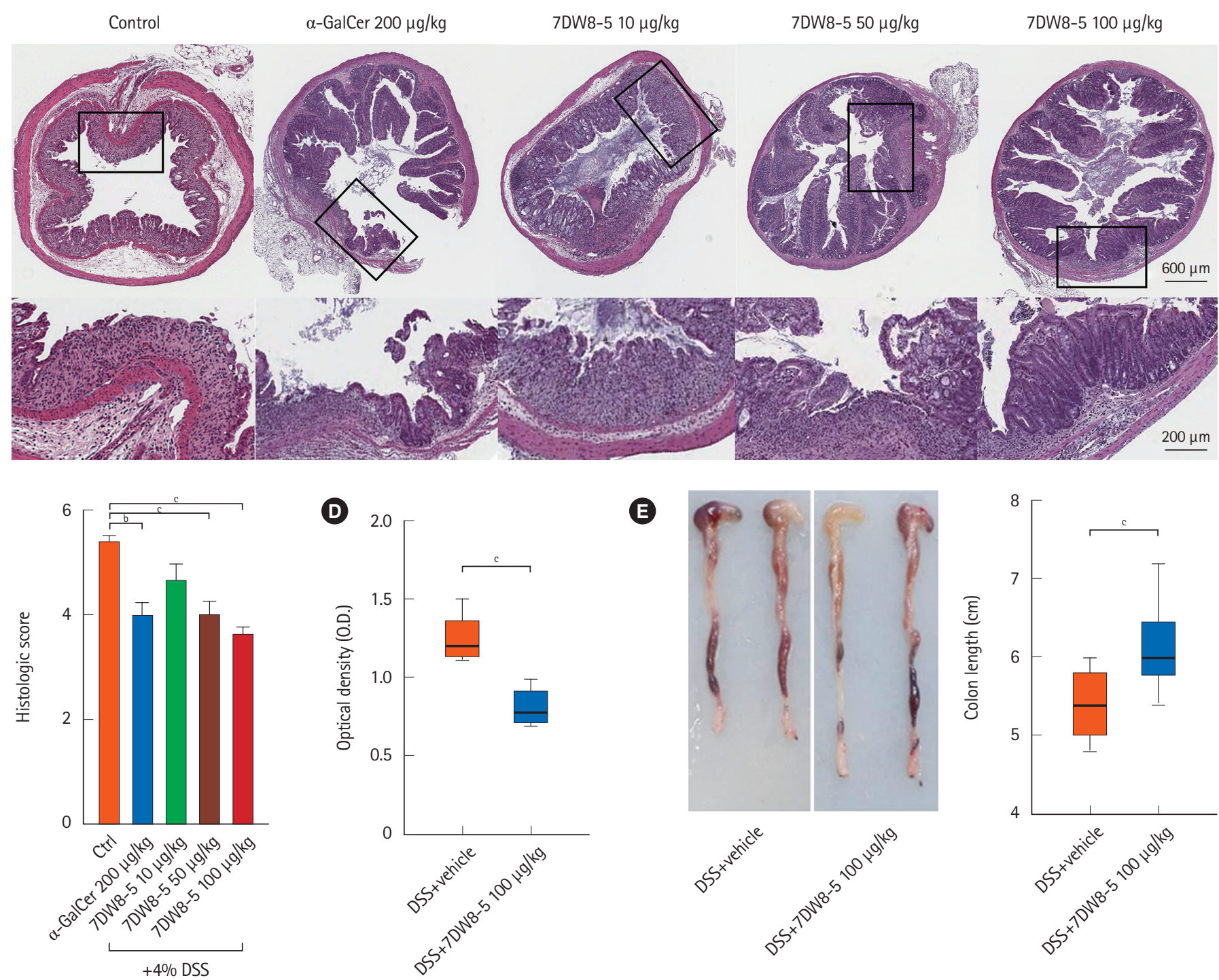

Fig. 2. The effect of 7DW8-5 on dextran sulfate sodium (DSS)-induced acute colitis. (A) The changes in body weight. (B) Disease activity index. (C) Histological score. Magnified image of the top black square is the bottom picture (H\&E). (D) Serum C-reactive protein level. (E) Colon length. ${ }^{\mathrm{a}} P<0.05,{ }^{\mathrm{b}} P<0.01,{ }^{\mathrm{c}} P<0.001$. $\alpha$-GalCer, $\alpha$-galactosylceramide. 


\section{Statistical Analysis}

The statistical significance of differences observed between experimental groups was analyzed using the Mann-Whitney $U$-test, Kruskal-Wallis test, one-way analysis of variance (ANOVA) and a two-way ANOVA with Bonferroni multiple comparisons with the statistical software GraphPad Prism (GraphPad Software, La Jolla, CA, USA). Statistical significance was set at the level of $P<0.05$.

\section{RESULTS}

The concentration of 7DW8-5 was variable, in agreement with previous work, ${ }^{12,13,16-20}$ so we administered $200 \mu \mathrm{g} / \mathrm{kg}$ of $\alpha$-GalCer or 10,50 , and $100 \mu \mathrm{g} / \mathrm{kg}$ of 7DW8-5 to the acute colitis model mice. The changes in DSS-induced acute colitis due to $\alpha$-GalCer or 7DW8-5 administration were evaluated by comparing the values for body weight change, DAI, colon length, serum CRP, and histologic score for $\alpha$-GalCer or 7DW8-5 administered mice to those for the mice administered vehicle only (Fig. 2). Increasing the injected dose of 7DW8-5 to 10, 50, and $100 \mu \mathrm{g} /$ $\mathrm{kg}$ resulted in improvements in body weight, DAI score, and histologic scores.

A two-way ANOVA with Bonferroni multiple comparisons revealed that weight loss was significantly increased in DSS/ vehicle group compared with the $\alpha$-GalCer $200 \mu \mathrm{g} / \mathrm{kg}$ (day 6 , $P<0.01$ and day $7, P<0.01$ ) and the 7DW8-5 $100 \mu \mathrm{g} / \mathrm{kg}$ group (day 5 , day 6 , and day $7 ; P<0.001$ ). The DAI scores were lower in the DSS/vehicle group than the $\alpha$-GalCer $200 \mu \mathrm{g} / \mathrm{kg}$ (day 4,
A

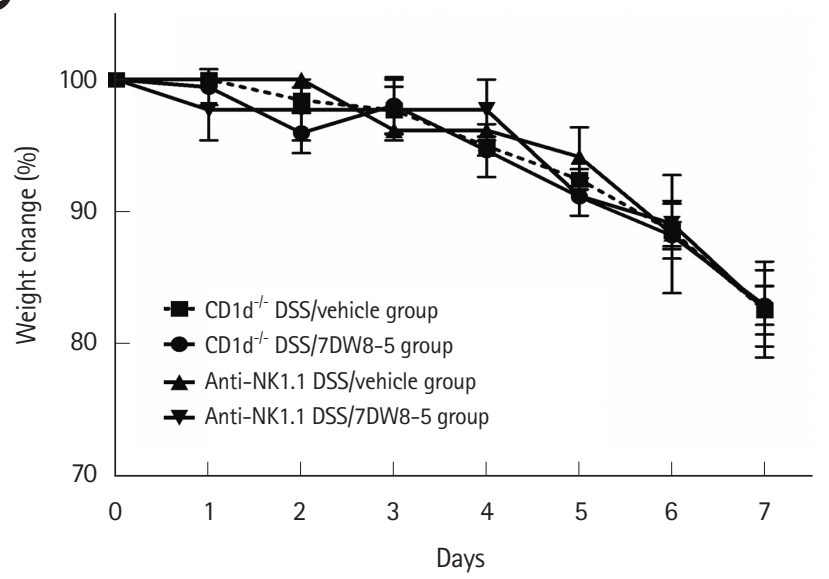

C

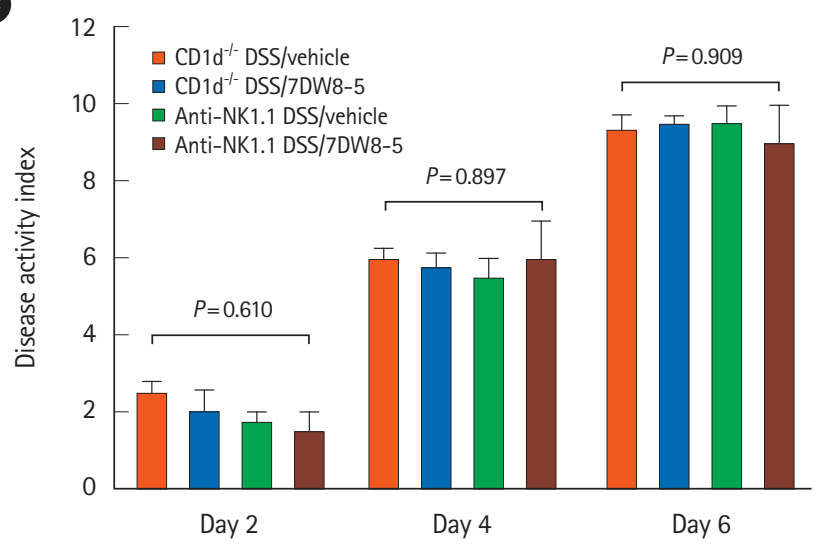

B

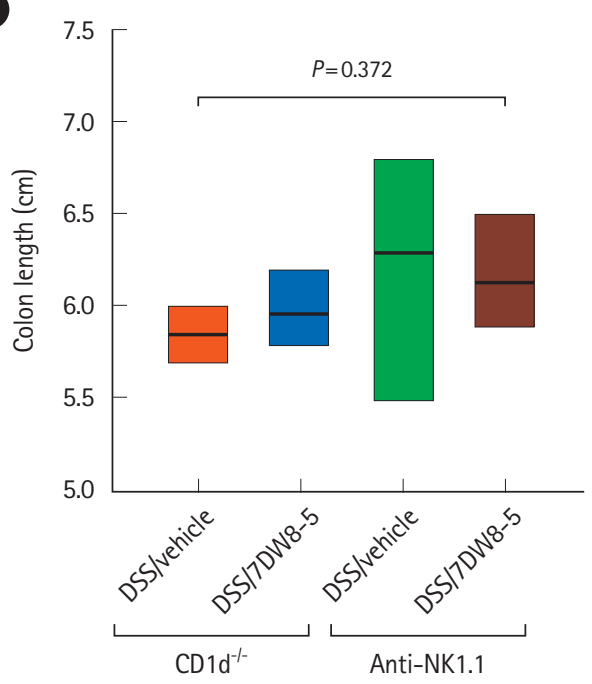

(D)

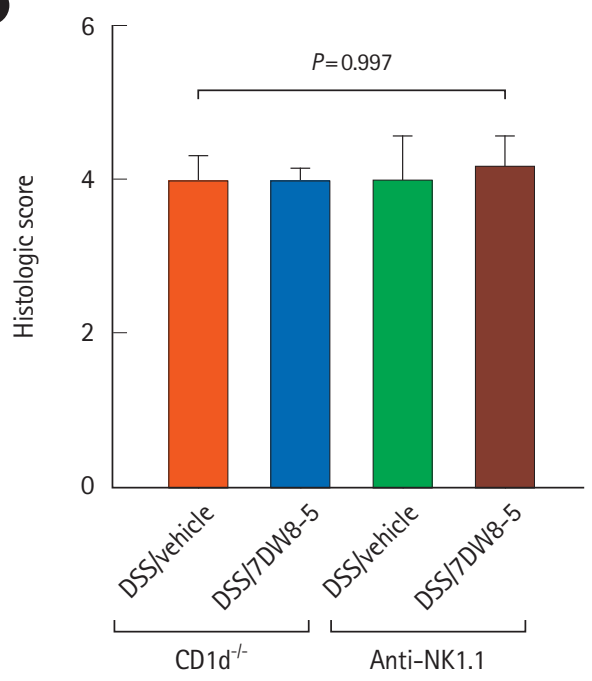

Fig. 3. The effect of 7DW8-5 on dextran sulfate sodium (DSS)-induced acute colitis in CD1d ${ }^{-1-}$ mice and anti-NK1.1 administrated C57BL/6 mice. (A) The changes in body weight. (B) Colon length. (C) Disease activity index. (D) Histological score. 
$P<0.05$ ) and the 7DW8-5 $100 \mu \mathrm{g} / \mathrm{kg}$ group (day 4 and day 6, $P<0.001)$. The histologic scores were significantly lower in the $\alpha$-GalCer $200 \mu \mathrm{g} / \mathrm{kg}(P=0.01)$, the 7DW8-5 $50 \mu \mathrm{g} / \mathrm{kg}(P=0.001)$, and the 7DW8-5 $100 \mu \mathrm{g} / \mathrm{kg}(P=0.001)$ than in the $10 \mu \mathrm{g} / \mathrm{kg}$ group. However, injection of a $200 \mu \mathrm{g} / \mathrm{kg}$ dose of 7DW8-5 into mice did not provide any additional improvement in colitis progression when compared to the $100 \mu \mathrm{g} / \mathrm{kg}$ dose (data not shown). The weight change, DAI score, and histologic analysis in mice administered $\alpha$-GalCer at $200 \mu \mathrm{g} / \mathrm{kg}$ were similar to those in mice administered 7DW8-5 at $50 \mu \mathrm{g} / \mathrm{kg}$ and were ameliorated compared with those in mice administered 100 $\mu \mathrm{g} / \mathrm{kg}$ of 7DW8-5. Therefore, administration of 7DW8-5 affected colitis in a dose-dependent manner up to a concentration of $100 \mu \mathrm{g} / \mathrm{kg}$. The total colon length was significantly shorter in the DSS/vehicle group than in the 7DW8-5 group $100 \mu \mathrm{g} / \mathrm{kg}$ group $(P<0.001)$. The level of CRP was significantly lower at day 7 in the serum of 7DW8-5 group $100 \mu \mathrm{g} / \mathrm{kg}$ group than in the DSS/vehicle group $(P=0.013)$.

The CD1d dependency of the reduction of the effects of 7DW8-5 was confirmed by administering 7DW8-5 or vehicle intraperitoneally to $\mathrm{CD}^{-/-}$mice and WT mice with anti-NK1.1 administration (Fig. 3). Subsequently, DSS-induced colitis was induced. No significant differences in weight loss $(P=0.993)$, DAI (day 2, $P=0.610$; day $4, P=0.897$; day 6, $P=0.909$ ), colon length $(P=0.372)$, or histologic score $(P=0.997)$ were observed. These findings indicated that 7DW8-5 could not protect against colitis in the $\mathrm{CD}^{-/-}$mice or in mice injected with anti-NK1.1 when compared with WT mice. Thus, 7DW8-5 showed its effects on intestinal inflammation in a CD1d-restricted manner.

Therefore, we determined whether 7DW8-5 in the presence of CD1d molecules activates NKT cells by measuring the percentage of NKT cells in colon tissues by FACS analysis. The
A

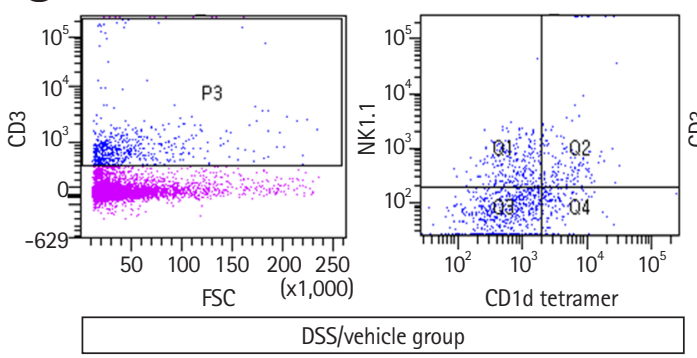

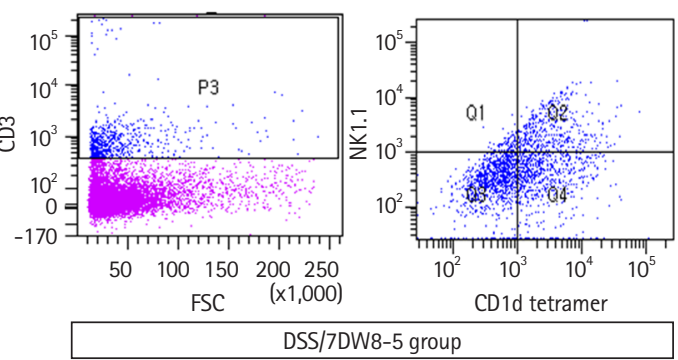

B

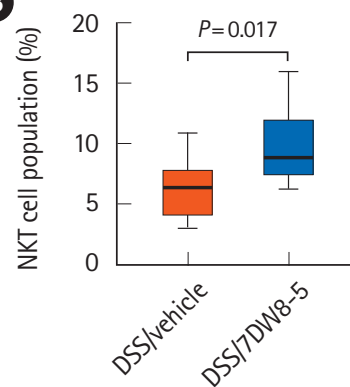

Fig. 4. Fluorescence-activating cell sorting for invariant natural killer T (iNKT) cell. (A) Gating strategy for flow cytometry analysis. (B) Percentage of NKT cell population in the colon tissue of the DSS/7DW8-5 group. FSC, forward scatter; DSS, dextran sulfate sodium.

(A)

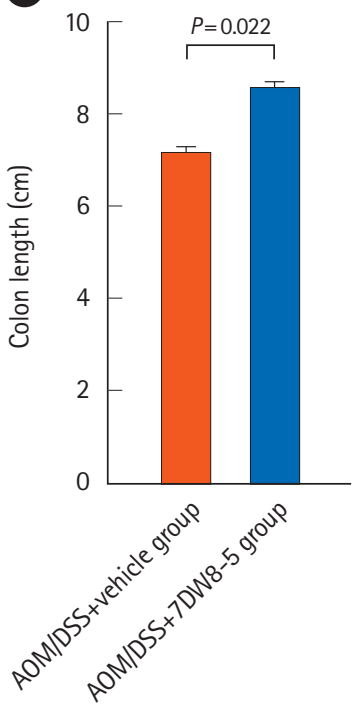

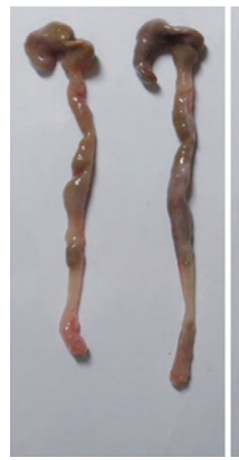
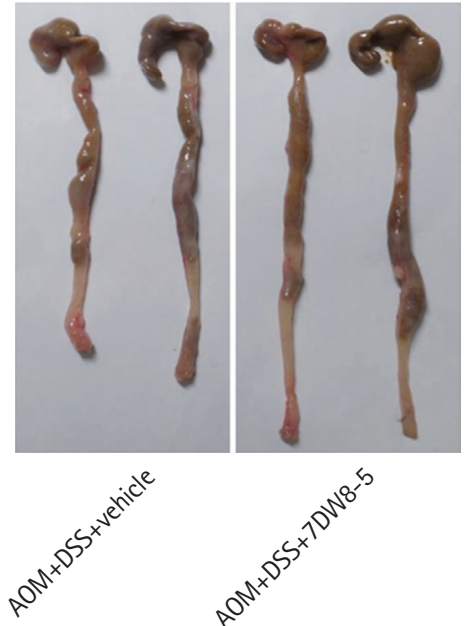

B

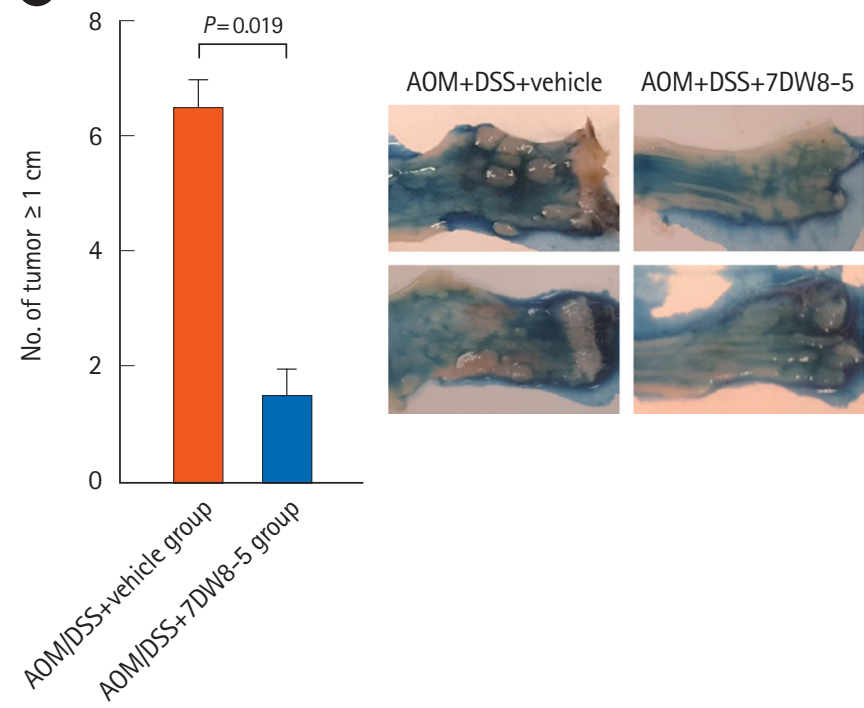

Fig. 5. The effect of 7DW8-5 in the chronic colitis-induced tumor model. (A) Colon length. (B) The number of tumors $\geq 1 \mathrm{~mm}$. AOM, azoxymethane; DSS, dextran sulfate sodium. 
A

\begin{tabular}{lc}
\hline Gene symbol & Log $_{2} \mathrm{FC}$ \\
\hline IL-1 $\alpha$ & -0.35 \\
IL-1 $\beta$ & -0.42 \\
IL-4 & 8.41 \\
IL-5 & 1.00 \\
IL-6 & 0.44 \\
IL-10 & -1.26 \\
IL-13 & 17.42 \\
IL-12 $\alpha$ & 0.68 \\
IL-12 $\beta$ & -1.10 \\
IL-17 $\alpha$ & 0.86 \\
IL-18 & -1.35 \\
IL-21 & 0.91 \\
IL-22 & 3.53 \\
IFN- $\gamma$ & 2.28 \\
\hline
\end{tabular}

B

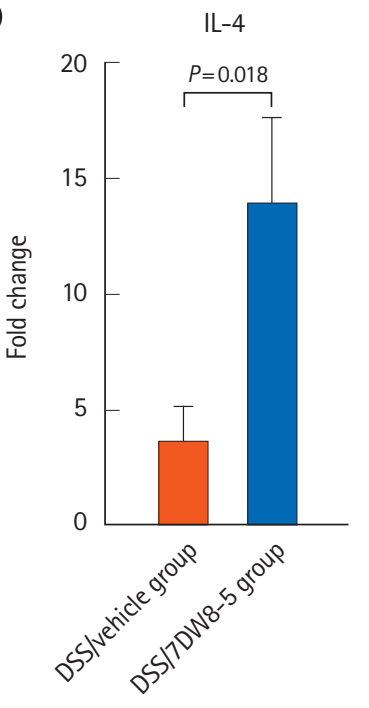

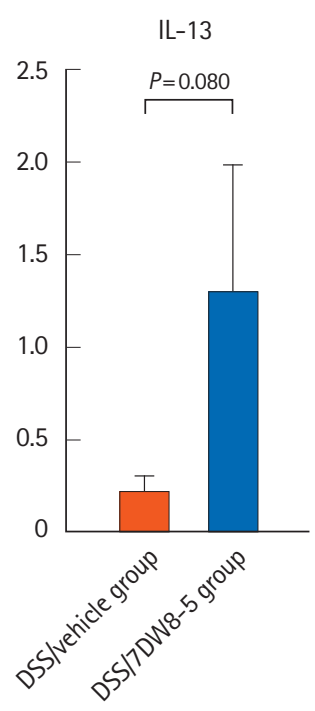

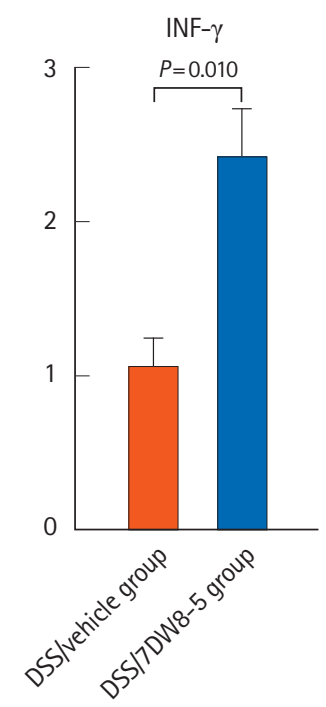

Fig. 6. Expression pattern of T helper type 1 (Th1) and Th2 cytokines in 7DW8-5 or vehicle only administrated dextran sulfate sodium (DSS)-induced acute colitis model. (A) Heatmap of differentially expressed cytokine genes. (B) Real-time quantitative polymerase chain reaction analysis for interleukin (IL)-4, IL-13, and interferon $\gamma(\mathrm{IFN}-\gamma)$.

population of NKT cells, which is characterized by CD3, NK1.1, and CD1d tetramer positive cells, was significantly higher $(P=$ 0.017 ) in the colon tissue of the DSS/7DW8-5 group than in colon tissues of the DSS/vehicle group (Fig. 4).

We evaluated the expression pattern of the DSS-induced acute colitis model after administration of 7DW8-5 by performing RNA-seq using total RNA obtained from colon tissues of the DSS/7DW8-5 and DSS/vehicle groups. The differential gene expression analysis revealed 325 differentially expressed genes filtered by absolute values of a fold change $>2$ or $<0.5$ between the 2 groups. A heatmap and hierarchical tree to compare the differences in gene expression between the group are illustrated in Supplementary Fig. 1A, and the functional category in gene ontology was selected for functional annotation (Supplementary Fig. 1B). We then focused on the cytokines of the DSS/ 7DW8-5 group and compared them to those of DSS/vehicle group. Among the Thelper type 1 (Thl) cytokines, interferon $\gamma($ IFN- $\gamma$ ), interleukin (IL)-12A, IL-17A, IL-21, and IL-22 showed increases and IL- $1 \alpha$, IL-1 $\beta$, IL-12 $\beta$, and IL-18 showed decreases (Fig. 5A). Conversely, the expression of Th2 cytokines, such as IL-4, IL-5, IL-6, and IL-13, showed an increasing pattern, whereas the levels of anti-inflammatory cytokine IL10 decreased (Fig. 6A). The qPCR for IL-4, IL-13, and IFN- $\gamma$ confirmed the expression of these cytokines (Fig. 6B).

We also tested 7DW8-5 for its effects on the chronic colitis- induced tumorigenesis in the AOM/DSS mouse model. Administration of 7DW8-5 to the AOM/DSS model resulted in a greater colon length $(P=0.022)$ (Fig. $5 \mathrm{~A})$ and a lower number of tumors $\geq 1 \mathrm{~mm}(P=0.019)$ (Fig. $5 \mathrm{~B})$ when compared to the AOM/DSS model administered vehicle only.

\section{DISCUSSION}

NKT cells are rare, but they play a pivotal role in the immune system. Exposure of these cells to glycolipid antigens causes them to secrete a multitude of specific cytokines that modulate both innate and adaptive immunity. Recent evidence has clearly established the importance of NKT cells in human health and disease. ${ }^{1}$ Several clinical trials using $\alpha$-GalCer, the first synthetic and now a well-known glycolipid, demonstrated the safety of parenteral administration; however, its efficacy was only marginal. ${ }^{13,21-24} 7$ DW8-5 is a biologically more potent analog of $\alpha$-GalCer ${ }^{12}$ and is viewed as a promising immunotherapeutic agent, especially as a potential vaccine adjuvant for malaria, HIV, and tuberculosis. ${ }^{12,13,18}$ Previous reports have indicated that $\alpha$-GalCer ameliorates the intestinal inflammation induced by DSS; ${ }^{10}$ however, 7DW8-5 has not yet been evaluated for its effects on intestinal inflammation. In the present study, we demonstrated that 7DW8-5 activates CD1d-restricted NKT cells through CDld and provides a protective effect against 
intestinal inflammation in mice. Not surprisingly, this effect of 7DW8-5 on intestinal inflammation was totally abolished in mice lacking CDld expression, confirming that the immunomodulatory effect of 7DW8-5 is driven by a CD1d-based mechanism.

RNA-seq was performed to identify the underlying immune response and the differential gene expression between the DSS/7DW8-5 group and the control, focusing on the cytokines, were evaluated. We selected and analyzed all detectable expression data for the Th1 and Th2 cytokines from the entire data set of RNA-seq. The RNA-seq data included the expression level of 27 genes associated with Thl pathway, 23 genes associated with the Th2 pathway, and 45 genes associated with the Th17 pathway (Supplementary Table 1). However, our data indicated an insufficient expression change for most of the Thl and Th2 cytokines and the results did not meet statistical significance. As a well-known Th1-biasing synthetic glycolipid, 7DW8-5 elicited a strong IFN- $\gamma$ response, a Thl response. In addition, we found that Th2 cytokine like IL-4 and IL-13, most of which may serve in protecting the intestine from inflammation, was increased in DSS/7DW-8 group. ${ }^{5}$ Our opinion regarding this finding is that even though an accumulation of CDld-restricted NKT cells occurred in the DSS/7DW8-5 group, these cells still represented a small population in the whole colon tissue. Thus, the absolute level of cytokines derived from NKT cells represents only a limited amount of the total RNA samples and could be below the cutoff threshold value. Furthermore, DSS administration causes colitis in NKT cell-deficient mice, suggesting that NKT cells may not be critical in the induction of colitis. ${ }^{14}$ This could be one of the reasons that the present study could not show any significant change of Th1 and Th2 cytokines

NKT cells have been proposed to have either protective or pathogenic roles, depending on the nature of the inflammatory stimuli and the possible lipid antigens that are recognized. ${ }^{2,25}$ In animal models, the protective role of NKT cells against intestinal inflammation has been reported in murine colitis models. ${ }^{15,25}$ 7DW8-5 elicited mixed effects on the Th1, Th2, and Th17 pathways, even though there were no significantly different expression patterns of the Th1, Th2, and Th17 pathway associated genes between the DSS/vehicle group, DSS/ $\alpha$-GalCer group, and DSS/7DW8-5 group. Nevertheless, when compared to the DSS/vehicle group, the expression was increased for 7 genes in the Th1 pathway, 5 genes in the Th2 pathway, and 11 genes in Th17 pathway in the DSS/ $\alpha$-GalCer group, whereas the expression was increased for 13 genes in Thl pathway, 10 genes in Th2 pathway, and 23 genes in Th17 pathway in DSS/
$\alpha$-7DW8-5 group. A comparison with the DSS/ $\alpha$-GalCer group revealed increased expression of 22 genes in the Thl pathway, 15 genes in the Th2 pathway, and 36 genes in the Th17 pathway in DSS/7DW8-5 group. Our data indicated that 7DW8-5 treatment could induce the expression of Thl/Thl7 associated genes, as well as the expression of Th2 associated genes. These results suggested that an alteration in the balance between the Thl/ Th17 and Th2 was induced by 7DW8-5 administration as part of the response against DSS-induced colitis, as if the well-known glycolipid, $\alpha$-GalCer, induced an alteration of the Th1/Th2 balance and improved colitis in the DSS colitis model. ${ }^{25-27}$ NKT cells have been proposed to have either protective or pathogenic roles, depending on the nature of the inflammatory stimuli and the possible lipid antigens that are recognized. ${ }^{2,25}$

In conclusion, the activation of NKT cells by 7DW8-5 in the presence of $\mathrm{CD} 1 \mathrm{~d}$ provides protection against colitis in mice. 7DW8-5 has been studied as a vaccine adjuvant and potential cancer treatment to date, but investigations into its use as a potential immune regulatory agent in immunologic disease, and especially IBD, have been limited. In the present study, we demonstrated that the 7DW8-5 glycolipid adjuvant provides a protective effect against colonic inflammation in mice, catalyzed by the recruitment of CD1d-restricted NKT cells, and that 7DW8-5 is more potent than the well-established glycolipid, $\alpha$-GalCer. This concept can translate to human trials, because 7DW8-5 offers a promising potential mechanism for the regulation of the immune response at a relatively low dosage and cost.

\section{FINANCIAL SUPPORT}

This work was supported by the National Research Foundation of Korea (NRF) grant funded by the Korean Government (2017R1A2B4006767) and research grant funded by the Korean Association for the Study of Intestinal Diseases.

\section{CONFLICT OF INTEREST}

No potential conflict of interest relevant to this article was reported.

\section{AUTHOR CONTRIBUTION}

Conceptualization: Lee C, Hong SN, Kim YH. Methodology: Lee C. Formal analysis: Lee C, Hong SN. Funding acquisition: Hong SN, Kim YH. Visualization: Lee C, Hong SN. Writing - 
original draft: Lee C. Writing - review and editing: Lee C, Hong SN, Kim YH. Approval of final manuscript: all authors.

\section{ORCID}

Lee C https://orcid.org/0000-0003-3992-9645

Hong SN https://orcid.org/0000-0002-4140-3717

Kim YH https://orcid.org/0000-0003-1803-2513

\section{SUPPLEMENTARY MATERIAL}

Supplementary materials are available at the Intestinal Research website (https://www.irjournal.org).

\section{REFERENCES}

1. Carreño LJ, Saavedra-Ávila NA, Porcelli SA. Synthetic glycolipid activators of natural killer T cells as immunotherapeutic agents. Clin Transl Immunology 2016;5:e69.

2. van Dieren JM, van der Woude CJ, Kuipers EJ, et al. Roles of CD1d-restricted NKT cells in the intestine. Inflamm Bowel Dis 2007;13:1146-1152.

3. Terabe M, Berzofsky JA. The role of NKT cells in tumor immunity. Adv Cancer Res 2008;101:277-348.

4. Middendorp S, Nieuwenhuis EE. NKT cells in mucosal immunity. Mucosal Immunol 2009;2:393-402.

5. Tefit JN, Davies G, Serra V. NKT cell responses to glycolipid activation. Methods Mol Biol 2010;626:149-167.

6. Van Kaer L. Natural killer T cells as targets for immunotherapy of autoimmune diseases. Immunol Cell Biol 2004;82:315-322.

7. Wu L, Van Kaer L. Natural killer T cells and autoimmune disease. Curr Mol Med 2009;9:4-14.

8. O'Keeffe J, Podbielska M, Hogan EL. Invariant natural killer T cells and their ligands: focus on multiple sclerosis. Immunology 2015;145:468-475.

9. Kawano T, Cui J, Koezuka Y, et al. CD1d-restricted and TCRmediated activation of valphal 4 NKT cells by glycosylceramides. Science 1997;278:1626-1629.

10. Saubermann LJ, Beck P, De Jong YP, et al. Activation of natural killer $\mathrm{T}$ cells by alpha-galactosylceramide in the presence of CD1d provides protection against colitis in mice. Gastroenterology 2000;119:119-128.

11. Wu D, Zajonc DM, Fujio M, et al. Design of natural killer T cell activators: structure and function of a microbial glycosphingolipid bound to mouse CDld. Proc Natl Acad Sci U S A 2006; 103:3972-3977.
12. Li X, Fujio M, Imamura M, et al. Design of a potent CDld-binding NKT cell ligand as a vaccine adjuvant. Proc Natl Acad Sci U S A 2010;107:13010-13015.

13. Padte NN, Boente-Carrera M, Andrews CD, et al. A glycolipid adjuvant, 7DW8-5, enhances CD8+ T cell responses induced by an adenovirus-vectored malaria vaccine in non-human primates. PLoS One 2013;8:e78407.

14. Kim JJ, Shajib MS, Manocha MM, Khan WI. Investigating intestinal inflammation in DSS-induced model of IBD. J Vis Exp 2012;(60):3678.

15. Kiesler P, Fuss IJ, Strober W. Experimental models of inflammatory bowel diseases. Cell Mol Gastroenterol Hepatol 2015; 1:154-170.

16. Xu X, Hegazy WA, Guo L, et al. Effective cancer vaccine platform based on attenuated salmonella and a type III secretion system. Cancer Res 2014;74:6260-6270.

17. Venkataswamy MM, Ng TW, Kharkwal SS, et al. Improving Mycobacterium bovis bacillus Calmette-Guèrin as a vaccine delivery vector for viral antigens by incorporation of glycolipid activators of NKT cells. PLoS One 2014;9:e108383.

18. Padte NN, Li X, Tsuji M, Vasan S. Clinical development of a novel CD1d-binding NKT cell ligand as a vaccine adjuvant. Clin Immunol 201 1;140:142-151.

19. Li X, Kawamura A, Andrews CD, et al. Colocalization of a CD1d-binding glycolipid with a radiation-attenuated sporozoite vaccine in lymph node-resident dendritic cells for a robust adjuvant effect. J Immunol 2015;195:2710-2721.

20. Coelho-Dos-Reis JG, Huang J, Tsao T, et al. Co-administration of alpha-GalCer analog and TLR4 agonist induces robust CD8(+) T-cell responses to PyCS protein and WT-1 antigen and activates memory-like effector NKT cells. Clin Immunol 2016;168:6-15.

21. Giaccone G, Punt CJ, Ando Y, et al. A phase I study of the natural killer T-cell ligand alpha-galactosylceramide (KRN7000) in patients with solid tumors. Clin Cancer Res 2002;8:3702-3709.

22. Ishikawa A, Motohashi S, Ishikawa E, et al. A phase I study of alpha-galactosylceramide (KRN7000)-pulsed dendritic cells in patients with advanced and recurrent non-small cell lung cancer. Clin Cancer Res 2005;11:1910-1917.

23. Nieda M, Okai M, Tazbirkova A, et al. Therapeutic activation of Valpha24+Vbetal 1 + NKT cells in human subjects results in highly coordinated secondary activation of acquired and innate immunity. Blood 2004;103:383-389.

24. Schneiders FL, Scheper RJ, von Blomberg BM, et al. Clinical experience with alpha-galactosylceramide (KRN7000) in patients with advanced cancer and chronic hepatitis $\mathrm{B} / \mathrm{C}$ infec- 
tion. Clin Immunol 2011;140:130-141.

25. Liao CM, Zimmer MI, Wang CR. The functions of type I and type II natural killer T cells in inflammatory bowel diseases. Inflamm Bowel Dis 2013;19:1330-1338.

26. El Haj M, Ben Yáacov A, Lalazar G, Ilan Y. Potential role of NKT regulatory cell ligands for the treatment of immune mediated colitis. World J Gastroenterol 2007;13:5799-5804.

27. Ru W, Peijie C. Modulation of NKT cells and Th1/Th2 imbalance after alpha-GalCer treatment in progressive load-trained rats. Int J Biol Sci 2009;5:338-343. 
See "A glycolipid adjuvant, 7DW8-5, provides a protective effect against colonic inflammation in mice by the recruitment of CD1 d-restricted natural killer T cells" on page 402-411.

A

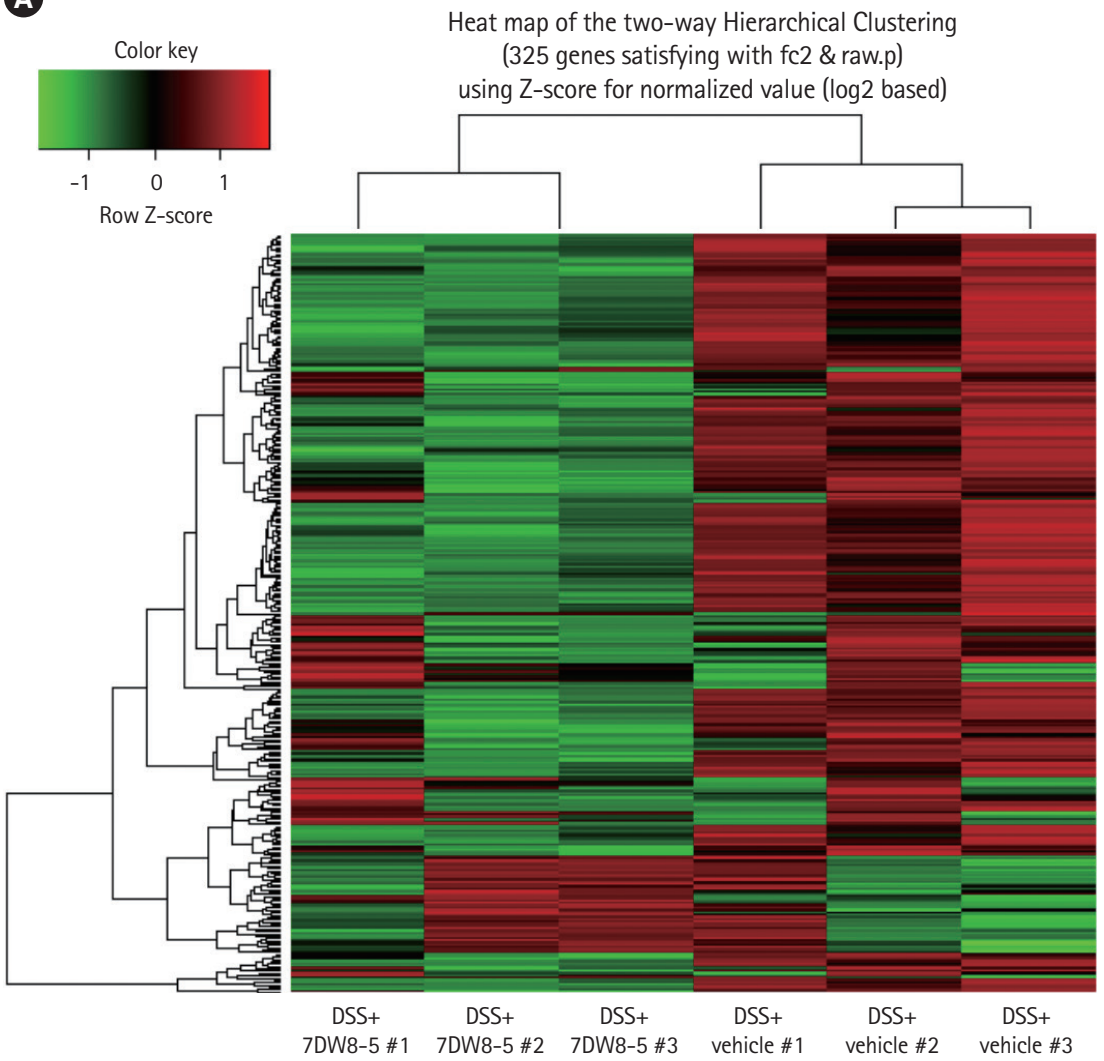

B
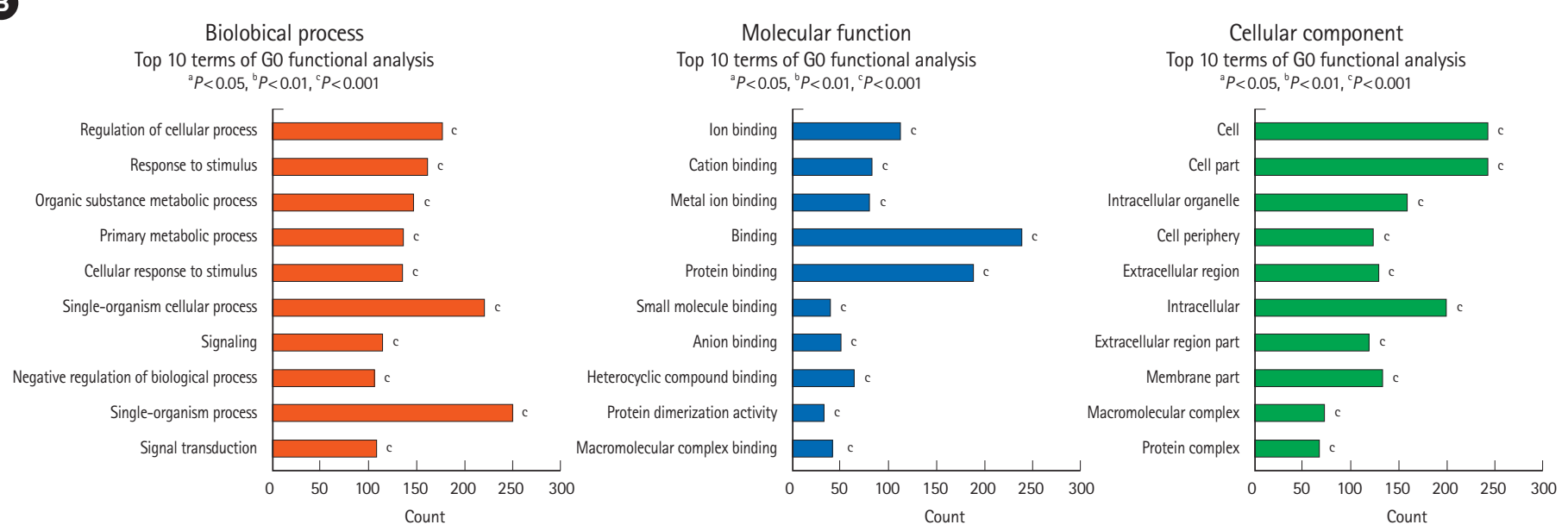

Supplementary Fig. 1. RNA-seq. (A) Heatmap and hierarchical tree comparing gene expression differences in colon tissue of, dextran sulfate sodium (DSS)/7DW8-5 mice compared to DSS/vehicle mice, (B) top 10 terms of gene ontology functional analysis. 


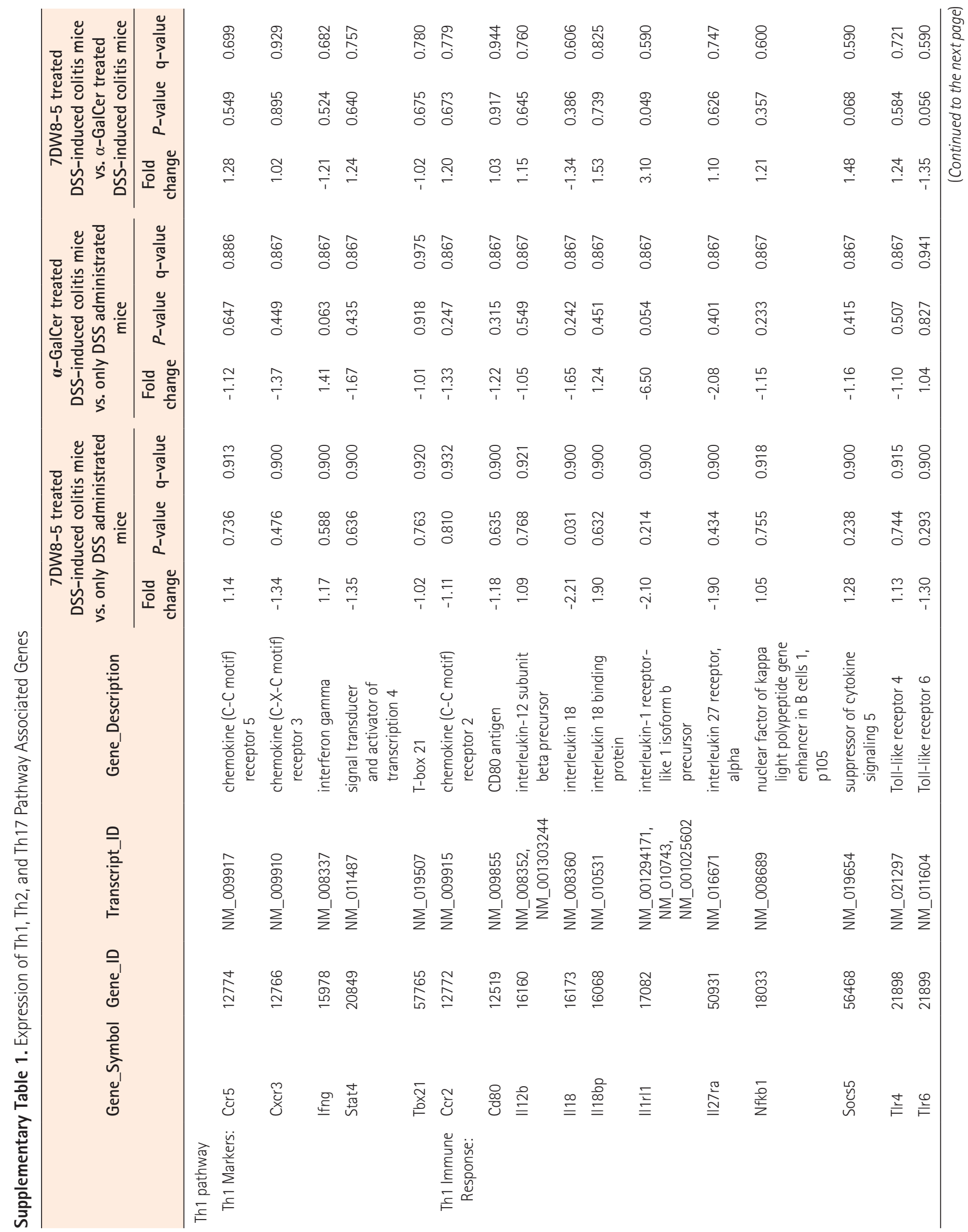




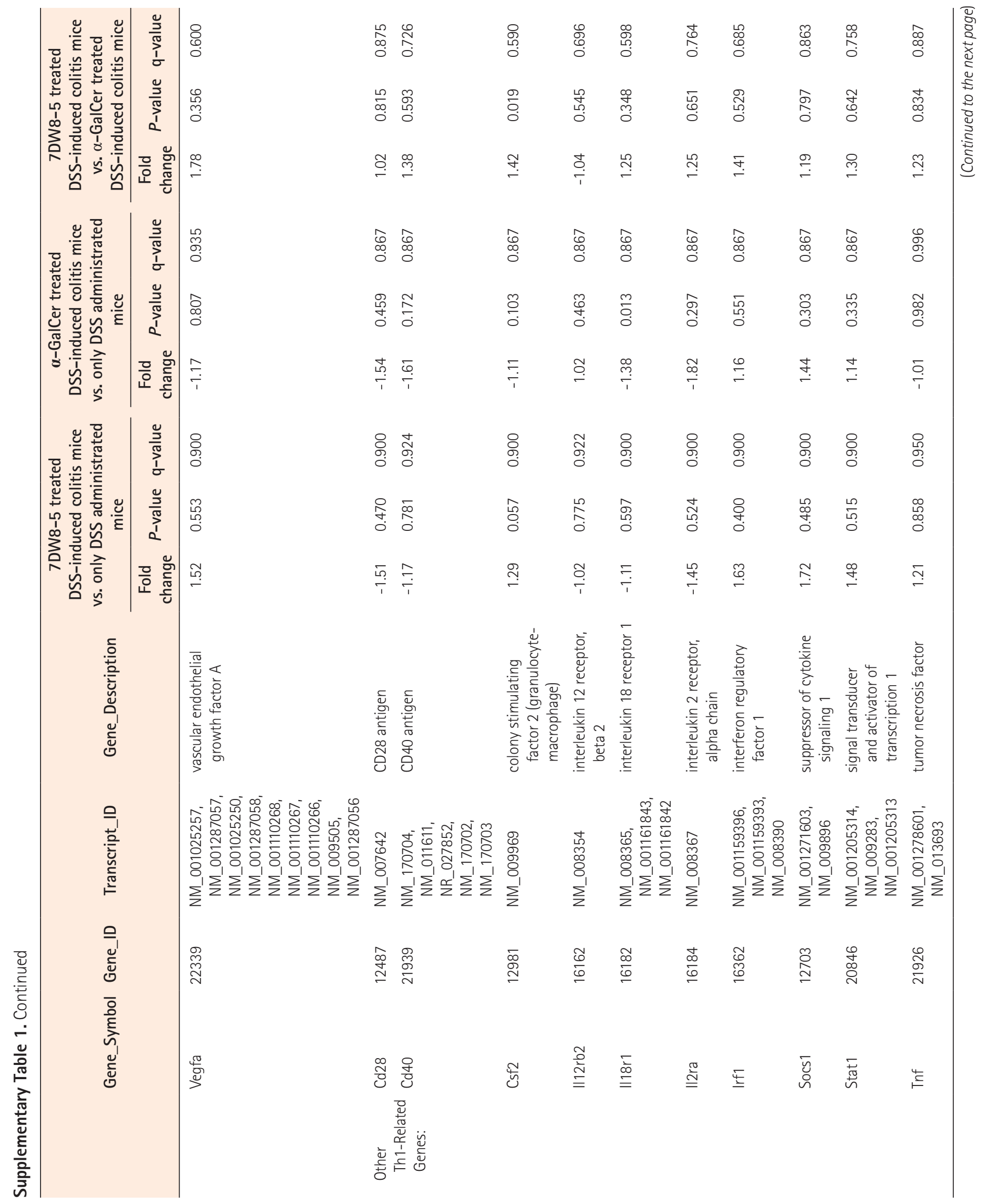




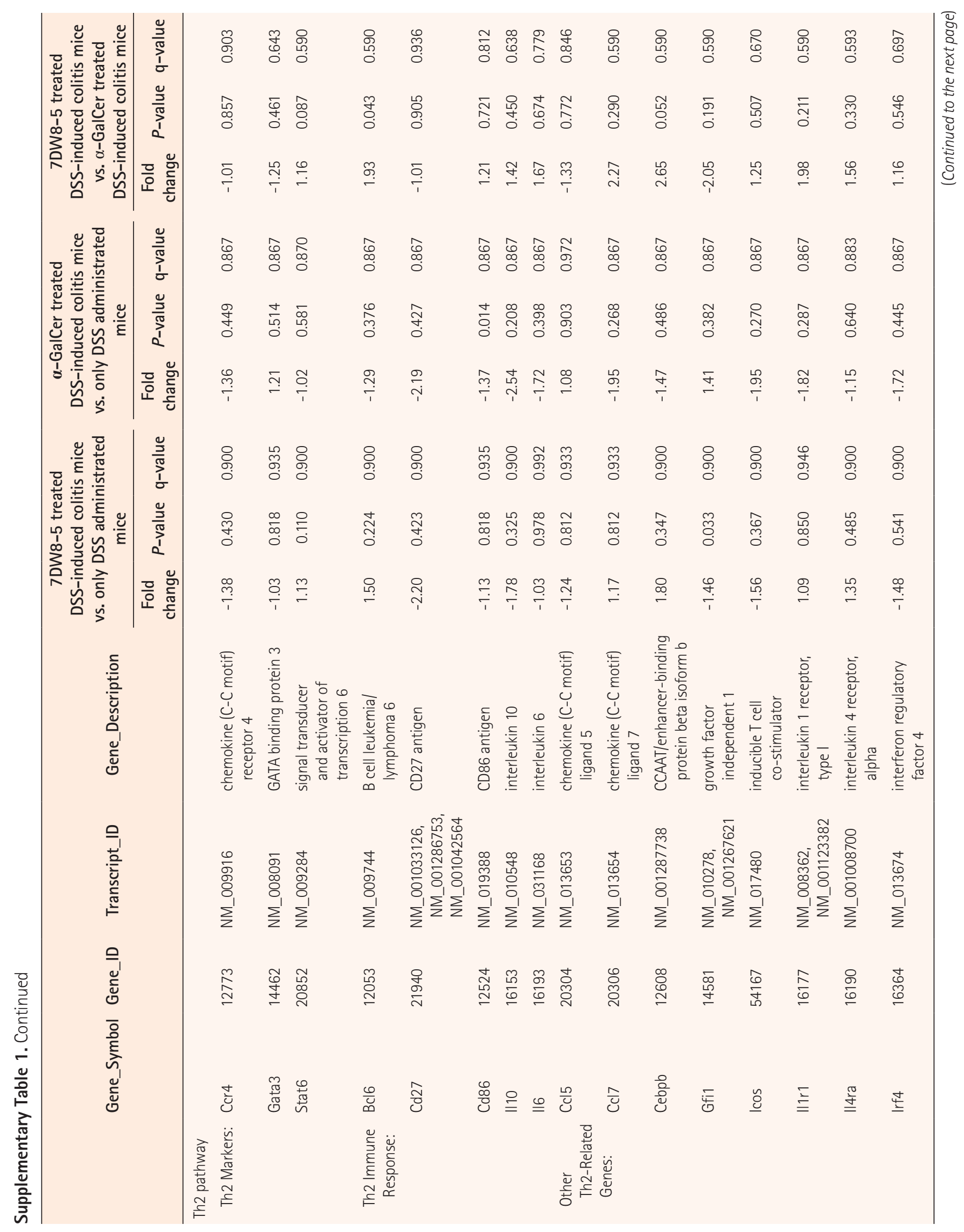




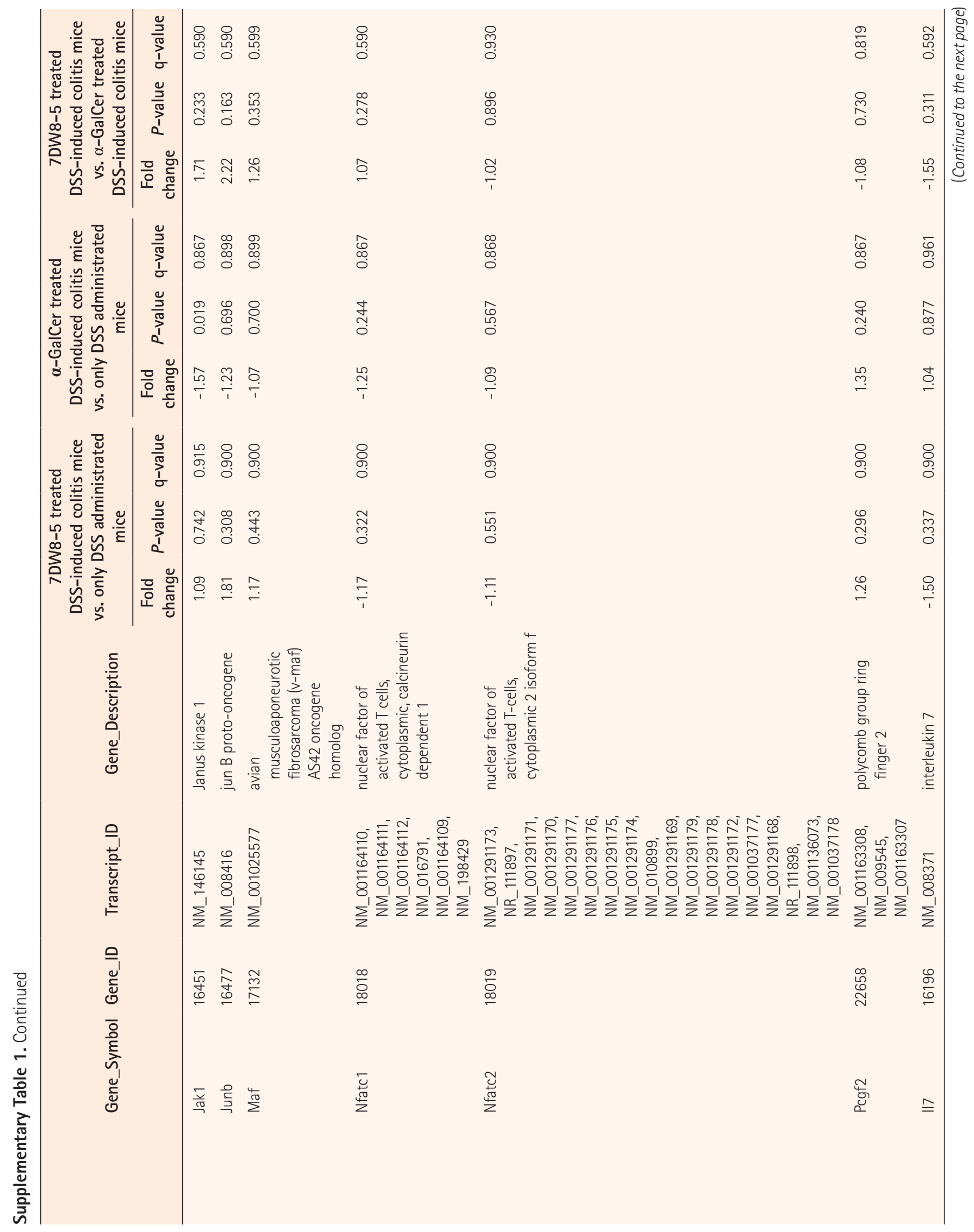




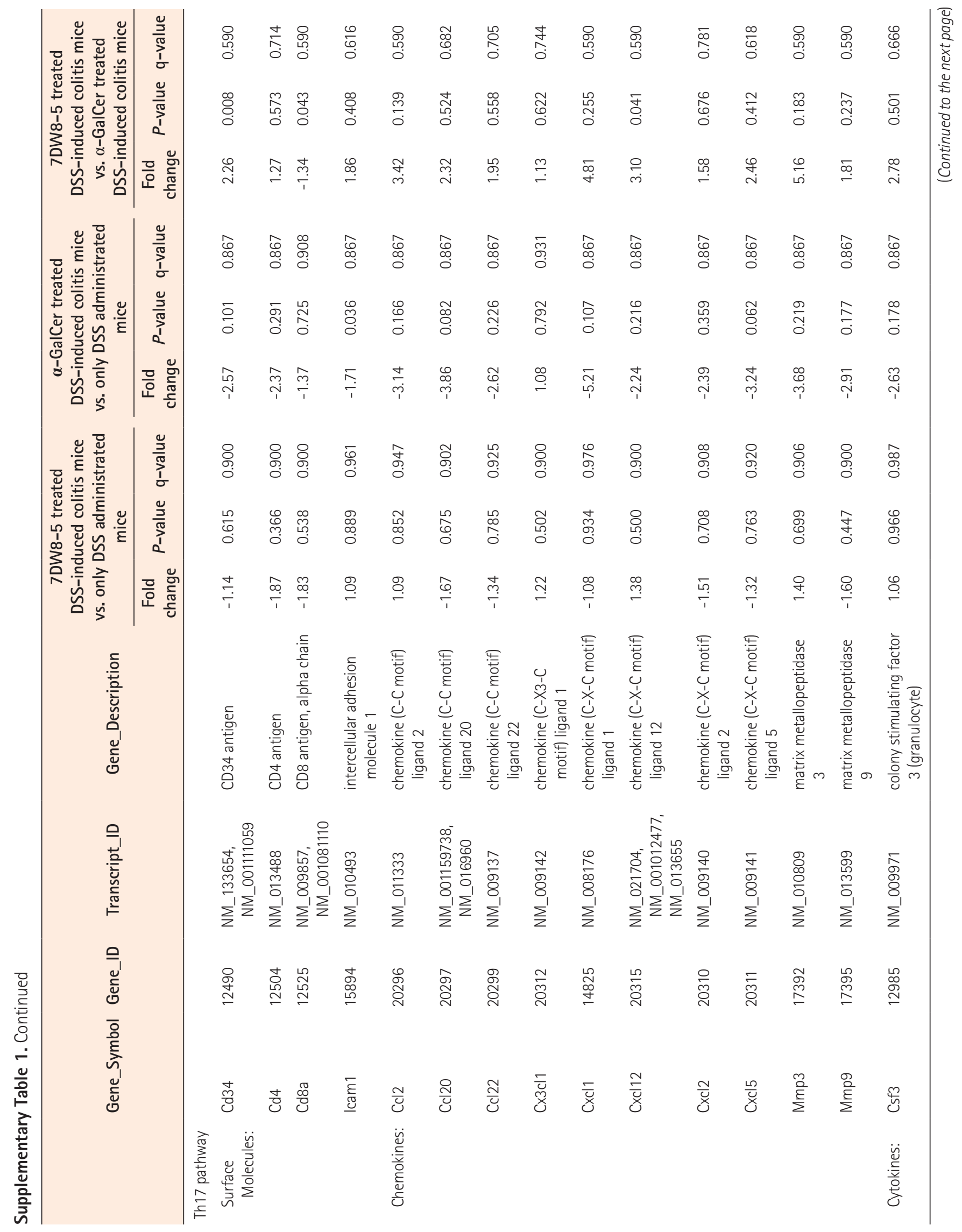




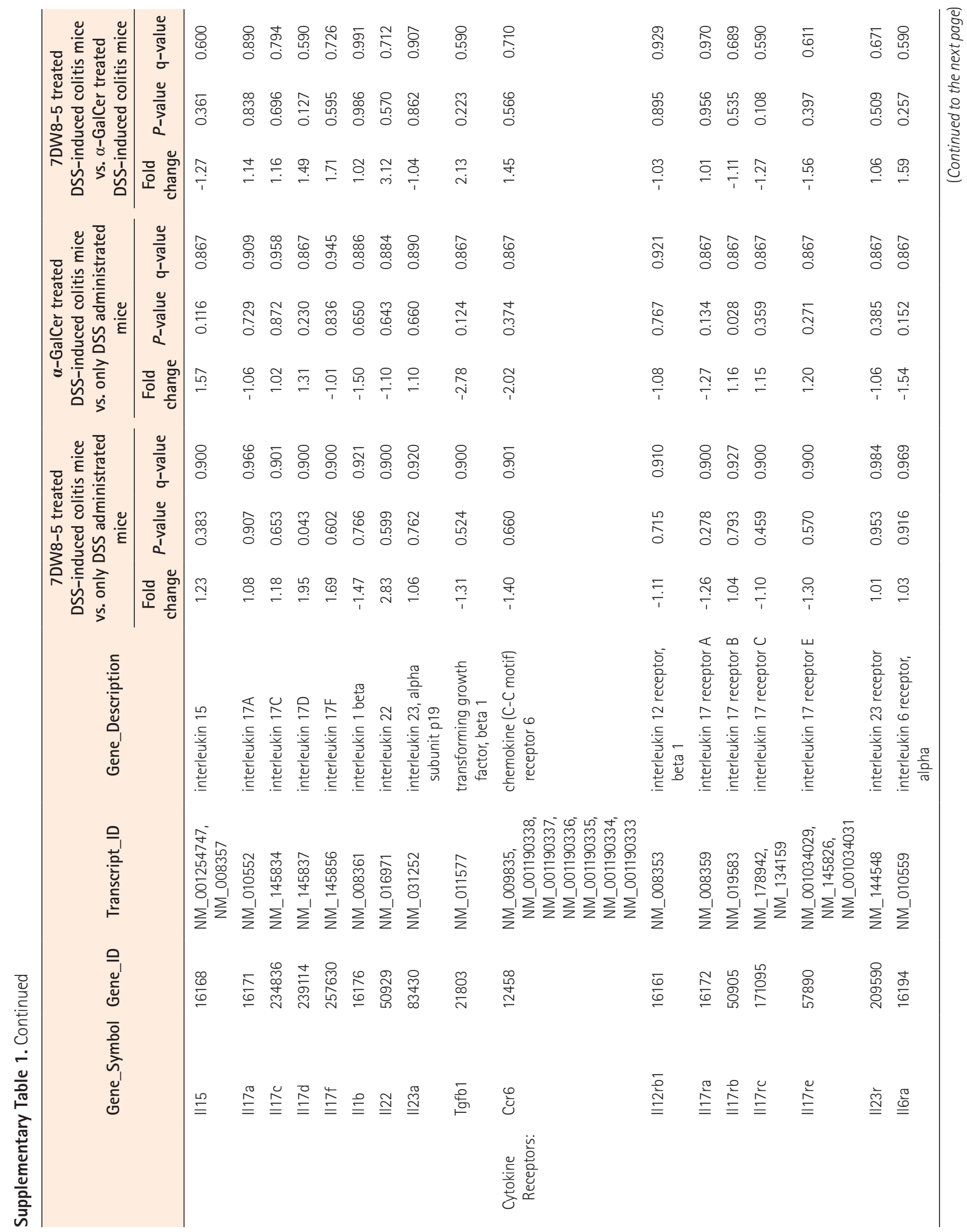




\begin{tabular}{|c|c|c|c|c|c|c|c|c|c|c|c|c|c|}
\hline \multirow{3}{*}{ 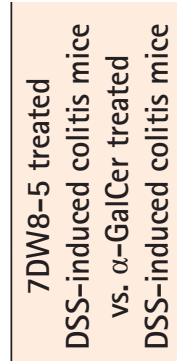 } & $\begin{array}{l}\frac{0}{5} \\
\frac{3}{50} \\
\frac{1}{0}\end{array}$ & 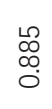 & 总 & 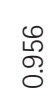 & $\begin{array}{l}\text { D̊ } \\
\text { Oे }\end{array}$ & 总 & 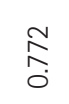 & 㕝 & 总 & 品 & 总 & $\begin{array}{l}\stackrel{8}{0} \\
0\end{array}$ & $\begin{array}{l}\text { Oo. } \\
0\end{array}$ \\
\hline & 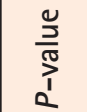 & $\begin{array}{l}\infty \\
\substack{0 \\
0 \\
0}\end{array}$ & $\stackrel{8}{\circ}$ & 总 & 管 & $\frac{\delta}{0}$ & $\begin{array}{l}\mathscr{8} \\
0 \\
0\end{array}$ & 㤩 & 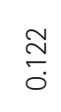 & 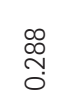 & $\begin{array}{l}\bar{\infty} \\
0 \\
0\end{array}$ & \begin{tabular}{l}
\multirow{ٌ}{0}{} \\
0 \\
0
\end{tabular} & $\begin{array}{l}\stackrel{\infty}{2} \\
0\end{array}$ \\
\hline & 흔 $\frac{\mathscr{g}}{\sigma}$ & $\stackrel{?}{\rightleftarrows}$ & $\stackrel{+}{i}$ & $\stackrel{\overbrace{}}{\infty}$ & $\stackrel{\infty}{\dddot{\sim}}$ & $\underset{+}{\mathbb{t}}$ & $\stackrel{F}{E}$ & 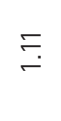 & $\stackrel{\text { ㅁ }}{\text { S }}$ & $\stackrel{\overline{\mathrm{N}}}{\text { in }}$ & 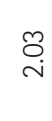 & 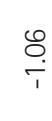 & 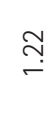 \\
\hline 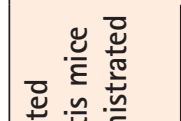 & $\begin{array}{l}\frac{0}{3} \\
\frac{5}{5} \\
\frac{1}{0}\end{array}$ & $\begin{array}{l}\text { के } \\
\text { o. } \\
0\end{array}$ & $\begin{array}{l}\infty \\
\infty \\
\infty \\
0\end{array}$ & $\begin{array}{l}0 \\
0 \\
0\end{array}$ & $\begin{array}{l}0 \\
\stackrel{8}{0}\end{array}$ & $\begin{array}{l}\stackrel{0}{0} \\
0 \\
0\end{array}$ & 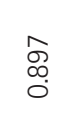 & $\begin{array}{c}\substack{\infty \\
\infty \\
\infty} \\
\end{array}$ & $\begin{array}{c}\mathscr{0} \\
\infty \\
0 \\
0\end{array}$ & $\begin{array}{l}\stackrel{\circ}{\circ} \\
\text { o. }\end{array}$ & $\begin{array}{l}\stackrel{0}{\infty} \\
0\end{array}$ & $\begin{array}{l}\text { o. } \\
\text { o. }\end{array}$ & $\begin{array}{l}\stackrel{0}{\infty} \\
0\end{array}$ \\
\hline 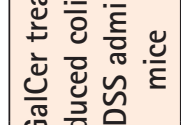 & 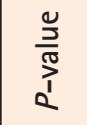 & $\begin{array}{l}\infty \\
\infty \\
0 \\
0\end{array}$ & 兽 & 疍 & $\begin{array}{l}\infty \\
\substack{y \\
0}\end{array}$ & సิ & : & ্ֻలુ & \&্ & $\begin{array}{l}\stackrel{\infty}{o} \\
\stackrel{0}{0} \\
0\end{array}$ & $\begin{array}{l}\text { ర్ } \\
\text { o }\end{array}$ & 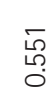 & ô. \\
\hline 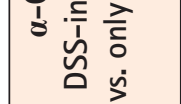 & 흔 은 & $\stackrel{t}{\leftrightarrow}$ & 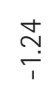 & $\stackrel{\infty}{i}$ & $\stackrel{+}{i}$ & $\stackrel{\circ}{T}$ & $\stackrel{\text { }}{\text { }}$ & $\stackrel{m}{T}$ & 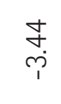 & $\stackrel{7}{t}$ & $\stackrel{\stackrel{m}{m}}{i}$ & $\stackrel{\infty}{\rightarrow}$ & $\stackrel{m}{\rightarrow}$ \\
\hline
\end{tabular}

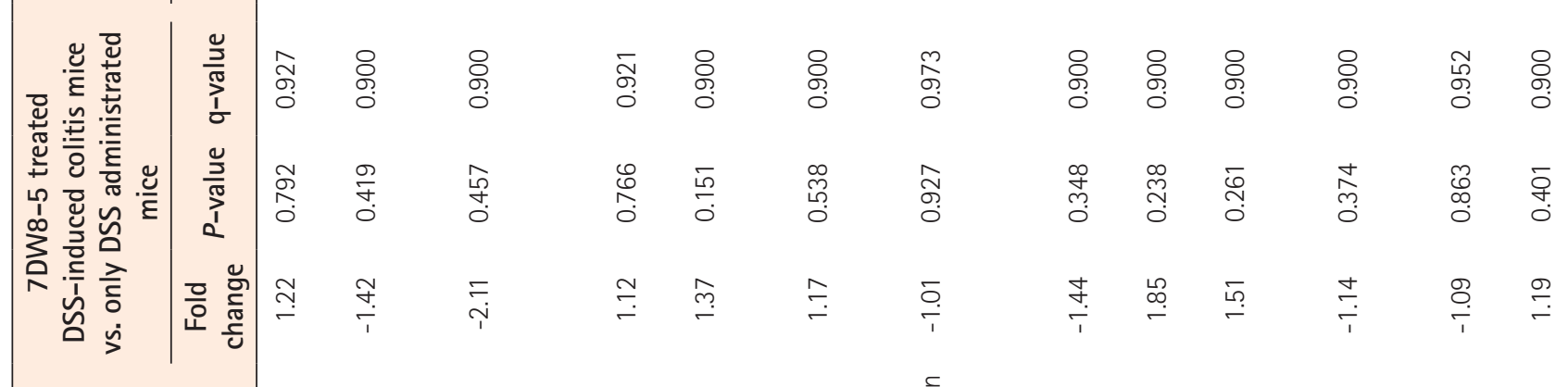

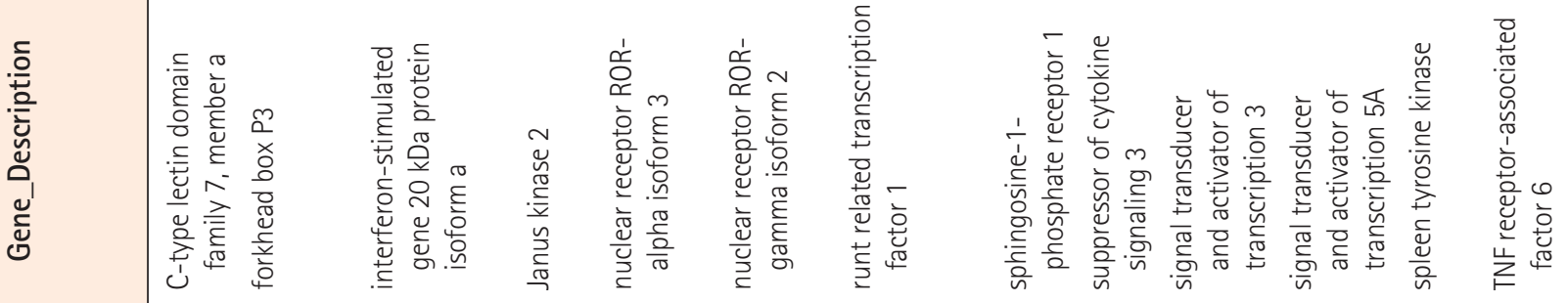

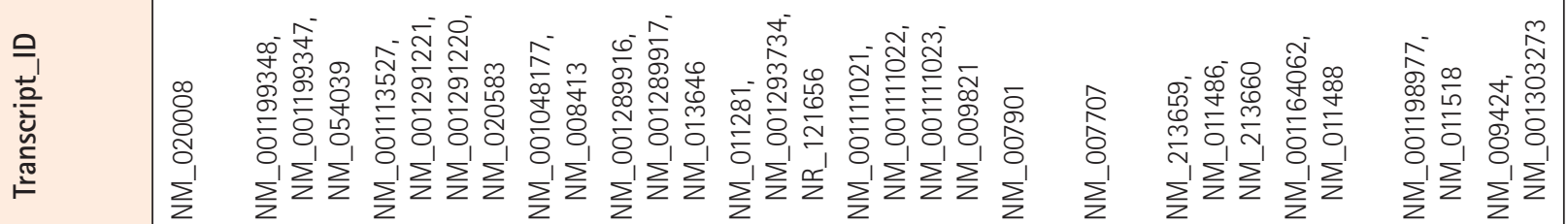

